\title{
Educação em direitos
}

\section{humanos na América Latina: fundamentos para uma prática educativa democrática}

- La educación en derechos humanos en América

Latina: bases para una práctica educativa democrática

- Human rights education in Latin America:

foundations for a democratic educational practice

Cristóvão Teixeira Rodrigues Silva'

Antonio Basilio Novaes Thomaz de Menezes²

Resumo: O presente trabalho busca compreender quais os fundamentos da Educação em Direitos Humanos (EDH) na América Latina, identificando as possíveis rupturas e continuidades com o projeto social delineado na Modernidade. $\mathrm{O}$ artigo parte da ideia que a sociabilidade moderna formou as bases das práticas educativas contemporâneas latino-americanas, que têm como elementos a emancipação humana através da produção racional e universal do conhecimento, economia capitalista e Estado centralizado. No percurso investigativo realizado, entende-se que por não serem monolíticos, o conjunto

1 Professor do Departamento de Direito da Universidade Regional do Cariri - URCA, Mestre em Ciências Jurídicas pela Universidade Federal da Paraíba - PPGCJ/UFPB, Aluno de Doutorado no Programa de Pós-graduação em Educação da Universidade Federal do Rio Grande do Norte - PPGEd/UFRN. cristovao.teixeira@urca.br

2 Professor Titular do Departamento de Filosofia, membro do Programa de Pós-graduação em Educação (PPGEd) e do Programa de Pós-graduação em Filosofia (PPGFil) da Universidade Federal do Rio Grande do Norte - UFRN. gpfe.ufrn@gmail.com 
de ideias, valores e crenças que formam a Modernidade apresentam tensões e conflitos internos, os quais não impediram o surgimento de um pensamento homogêneo e a colonização de múltiplos interesses sociais locais pela satisfação dos interesses econômicos globais. Em seguida, abordam-se os efeitos da adoção desse projeto na América Latina, marcado pela dominação direta dos colonizadores europeus, extermínio dos povos originários e sucessivos governos autoritários, emergindo práticas educativas que impedem o diálogo com o conhecimento local e a formação de cidadãos participativos. Por meio de uma abordagem qualitativa e revisão de literatura, é possível identificar que a EDH na América Latina se fundamenta na reflexão social crítica, que tem raízes nos preceitos da educação popular e movimentos sociais pró-democráticos, que buscam a ampliação da participação política popular. É possível concluir que o diálogo e a democracia são a um só tempo pré-condição e fim da prática da educação comprometida com a emancipação humana e a participação inclusiva. $\mathrm{O}$ desafio à manutenção de um programa permanente de EDH é a neutralização ou esvaziamento por interesses econômicos, antidemocráticos e de negação dos saberes locais.

Palavras-chave: Educação em direitos humanos. Modernidade. América Latina. Fundamentos sócio-históricos. Diálogo democrático.

Resumen: El presente trabajo busca comprender los fundamentos de la Educación en Derechos Humanos (EDH) en América Latina, identificando las posibles rupturas y continuidades con el proyecto social perfilado en la Modernidad. El artículo parte de la idea de que la sociabilidad moderna fue la base de las prácticas educativas latinoamericanas contemporáneas, cuyos elementos son la emancipación humana a través de la producción racional y universal del conocimiento, la economía capitalista y el estado centralizado. En el camino investigativo tomado, se entiende que por no ser monolíticos, el conjunto de ideas, valores y creencias que conforman la Modernidad presenta tensiones y conflictos internos, que no impidieron el surgimiento de un pensamiento homogéneo y la colonización de múltiples intereses sociales y culturales. para la satisfacción de los intereses económicos globales. Luego, se abordan los efectos de la adopción de este proyecto en América Latina, marcado por la dominación directa de los colonizadores europeos, el exterminio de los pueblos originarios y sucesivos gobiernos autoritarios, prácticas educativas emergentes que impiden el diálogo con los saberes locales y la formación de ciudadanos participativos. A través de un enfoque cualitativo y revisión de la literatura, es posible identificar que EDH en América Latina parte de una 
reflexión social crítica, que tiene sus raíces en los preceptos de la educación popular, defensora del diálogo con los saberes locales y movimientos sociales prodemocráticos. , que buscan ampliar la participación popular. Es posible concluir que el diálogo y la democracia son a la vez condición previa y fin de la práctica de una educación comprometida con la emancipación humana y la participación inclusiva, y es un desafío mantener un programa permanente que no se neutralice ni se vacíe.

Palabras clave: Educación en derechos humanos. América Latina. Fundamentos sociohistóricos. Democracia. Justicia social.

\begin{abstract}
The present work seeks to understand the fundamentals of Human Rights Education (HRE) in Latin America, identifying the possible ruptures and continuities with the social project outlined in Modernity. The article starts from the idea that modern sociability formed the basis of contemporary Latin American educational practices, whose elements are human emancipation through the rational and universal production of knowledge, capitalist economy and centralized state. In the investigative path taken, it is understood that because they are not monolithic, the set of ideas, values and beliefs that make up Modernity present internal tensions and conflicts, which did not prevent the emergence of homogeneous thinking and the colonization of multiple social and cultural interests by the satisfaction of global economic interests. Then, the effects of the adoption of this project in Latin America are approached, marked by the direct domination of European colonizers, the extermination of the original peoples and successive authoritarian governments, emerging educational practices that prevent dialogue with local knowledge and the formation of participatory citizens. Through a qualitative approach and literature review, it is possible to identify that HRE in Latin America starts from a critical social reflection, which has its roots in the precepts of popular education and pro-democratic social movements, which seek to expand popular political participation. It is possible to conclude that dialogue and democracy are both a precondition and an end to the practice of education committed to human emancipation and inclusive participation. The challenge for maintaining a permanent HRE program is its neutralization or emptying due to economic, anti-democratic interests and the denial of local knowledge.
\end{abstract}

Keywords: Human rights education. Latin America. Socio-historical foundations. Democracy. Social justice. 


\section{Considerações iniciais}

As práticas educacionais, para sua boa compreensão, precisam ser analisadas a partir do contexto sócio-histórico e dos fundamentos que as orientam. A Educação em Direitos Humanos - EDH na América Latina, como estratégia de múltiplos processos e direcionada para a formação de cidadãos participantes, é uma prática recente, só possível após a inserção e apropriação do discurso de Direitos Humanos no continente. O contato com tais ideias não é fruto de transformações endógenas das culturas locais, mas tem como ponto de clivagem inicial o contexto de invasão e conquista do território americano, do qual resultaram intensos conflitos internos (políticos, sociais, econômicos e culturais).

Em mais de três séculos de dominação direta dos colonizadores europeus, extermínio dos povos originários e sucessivos governos autoritários, o contexto latino americano tem sido marcado por severa desigualdade social, negação da visão de mundo dos povos originários e cultura de intolerância. Os Estados locais, após a independência política, tentam reproduzir os mesmos ideais que marcaram os períodos anteriores. Nesse contexto, é preciso analisar em que medida os fundamentos sócio-históricos da Educação em Direitos Humanos - EDH foram ressignificados na América Latina, diante das continuidades e rupturas com os discursos - jurídico, político, educacional, econômico e cultural - da Modernidade.

A visão de mundo trazida pelos europeus, nos séculos XVI e seguintes, era baseada em um conjunto de valores, crenças e ideias que tinha no trabalho, na economia de mercado e na racionalidade voltada ao domínio e à conquista, alguns dos seus delineamentos. $\mathrm{O}$ antropocentrismo, o racionalismo e o cientificismo, nesse contexto, levariam à emancipação e à realização da dignidade humana, completando o plantel iluminista que formulou as bases da Modernidade. Tais ideais moldaram os países latino-americanos, destinando seus recursos humanos e ambientais para a satisfação de interesses externos e negando racionalidade ao conhecimento dos povos nativos. O resultado é uma sociedade desigual e pouco comprometida com valores de cooperação, solidariedade, diálogo e respeito às diferenças, o que se reflete nas práticas educativas.

Assim, o artigo busca, através de uma abordagem qualitativa, investigar os fundamentos sociais, históricos e filosóficos das práticas educativas comprometidas com os Direitos Humanos na América Latina. Por meio de uma pesquisa bibliográfica, é apresentado como os Direitos Humanos têm suas bases no pensamento da Modernidade e em que medida esses fundamentos foram inseridos e modificados no contexto latino-americano.

Identifica-se primeiro o compromisso dos Direitos Humanos com os ideais liberais de liberdades individual, econômica e política, mundializados 
pelos europeus dos séculos XVII ao XIX. Depois, apresenta-se o impacto da globalização no conjunto daquelas normas, situação que inseriu novos interesses à noção de Direitos Humanos, ligados à justiça e ao reconhecimento social. Esse segundo momento corresponde ao século XX, o qual foi palco de muitas demandas advindas de povos antes colonizados pelos europeus, entre os quais estão os países latino-americanos.

A análise dos fundamentos e compromissos da EDH na América Latina é feita em conjunto com a investigação da tensão nas propostas emancipadoras dos Direitos Humanos, que encontram limites em interesses econômicos e políticos globais e em práticas sociais autoritárias e na injustiça social. A EDH, como aponta a literatura apresentada, necessita de estruturas democráticas e promotoras do diálogo entre saberes locais e estrangeiros, sem hierarquização a priori e subalternização. A concretização de práticas educacionais, comprometidas com a realização plena da dignidade humana e formação para a cidadania, pressupõem a reflexão crítica sobre os seus fins, a íntima relação com o contexto em que é praticada e a formação de ambiente democrático capaz de sustentar o diálogo das diferenças.

\section{Práticas educativas na modernidade: tensão entre emancipação e regulação}

A busca por fundamentos das práticas educacionais passa pela descrição das técnicas e práticas pedagógicas e sua correspondente articulação social, histórica e filosófica. Nesses moldes, para se entender os pré-condições e os fins da educação na atualidade, faz-se necessário uma abordagem "[...] mais problemática e pluralista [...], tomando a noção de educação seja como conjunto de práticas sociais seja como feixe de saberes". (CAMBI, 1999, p. 24). Adota-se, como estratégia de investigação problemática e pluralista, a noção de contexto sócio-histórico para fundamentar as práticas e os saberes pedagógicos.

Para compreender quais os fundamentos da EDH no contexto específico da América Latina, faz-se necessário um retorno à formação das bases das práticas educativas, relacionando-o com o espaço-tempo de sua formação. Para Marques e Carvalho (2016), o que se denomina hoje como práticas educativas apresentam dois níveis. O primeiro diz respeito às "práticas educativas previstas pelos agentes educativos", o segundo designa a "interação entre professores e alunos, por meio das ações que compõem a atividade de ensino e aprendizagem" (p. 123). Inicialmente tem-se o nível organizativo, que é realização com a elaboração de planos, programas e diretrizes. Já o nível executivo envolve as ações pedagógicas adotadas, que intermediam a relação entre os professores e os estudantes. Em geral, os dois níveis apresentam 
os mesmos fundamentos orientadores, mas que podem não estar articulados com o contexto da sua execução. Esta tensão entre fundamento e contexto sócio-hitórico pode ser observada no EDH, por isso a necessidade de remontar ao período da Modernidade, especialmente por duas razões.

Primeiro, é o tempo/espaço do delineamento das noções de Direitos Humanos e das bases das práticas pedagógicas ocidentais, que tomam do Renascimento e do lluminismo a 'formação da consciência individual e do empenho produtivo' (CAMBI, 1999, p. 141). A centralidade do individualismo será a matriz das normas jurídicas de limitação do poder das instituições sociais e ampliação do espaço da razão como produtora do conhecimento, mitigando o papel da coletividade e das fontes não humanas de saberes (BOBBIO, 2004). Segundo, é nesse período (século XVI) que os europeus chegam à América Latina, introduzindo práticas sociais em substituição das locais, por meio de uma dominação direta que durou até o século XIX, em algumas partes. Restaram marcas indeléveis na formação das instituições e práticas sociais posteriores.

A Modernidade, como aqui mencionada, diz respeito ao período de formação dos "[...] costume de vida ou organização social que emergiram na Europa a partir do século XVII, e que ulteriormente se tornaram mais ou menos mundiais em sua influência". (GIDDENS, 1991, p.11). É possível traçar algumas rupturas com as práticas sociais que identificaram a Idade Média. Por exemplo, neste período a educação era realizada majoritariamente por instituições religiosas cristãs e tinham no aperfeiçoamento espiritual algumas das suas características. Na Modernidade, a educação passa a se fundamentar em valores laicos, fazendo surgir instituições educativas sem o compromisso religioso cristão. A liberdade e a emancipação humana, a pluralidades de classes e práticas sociais fazem parte do novo sistema organizativo que tem no indivíduo o seu eixo central. As práticas educativas são direcionadas para sustentar a nova configuração emergente, baseada no sistema econômico capitalista, no Estado centralizado, na laicização e emancipação do conhecimento das visões religiosas. (CAMBI, 2011).

Os fins da educação moderna são a construção de um "indivíduo ativo na sociedade, [...] aberto para o cálculo racional da ação e suas consequências [...]". (CAMBI, 2011, 198). Há um compromisso com a transformação do mundo medieval e o estabelecimento de condições que sustentem e mantenham essa nova configuração, com bases terrenas e não espirituais, o qual se delineia de forma mais definida em meados do século XV (p. 195). A partir da Europa, especialmente com os processos de colonização, tais ideias são espaIhadas pelo mundo, produzindo severas mudanças globais, atreladas à noção de conquista, desenvolvimento e progresso. As comunidades passam a ser classificados a partir de escalas evolutivas que variam entre desenvolvidos e 
subdesenvolvidos, civilizados e bárbaros, racionais e animalescos.

A noção de sujeito passa a ser formada por um discurso social, filosófico e político que toma o modelo europeu (desenvolvido, civilizado, capitalista) como parâmetro e finalidade universais. Tal concepção é adequada à necessidade de justificar e impulsionar a conquista e dominação de novos territórios e povos, conformando-os ao sujeito moderno que pressupõe razão, verdade e progresso.

O encadeamento desses três elementos dá-se da seguinte forma: na economia, o feudalismo dá lugar ao capitalismo; na política, o Estado assume as funções sociais anteriormente atribuídas à igreja e à família; na comunidade, as relações sociais são laicizadas e racionalizadas, "[...] produzindo uma revolução profunda nos saberes que se legitimam e se organizam através do uso da razão". (CAMBI, 1999, p. 198). No século XVI, o projeto da Modernidade tem como dimensões a secularização, o individualismo, a economia de mercado e a sociedade de classe, com um novo sujeito, "[...] segundo modelos sociais de comportamento, tornando-o produtivo e integrado". (p. 199-200).

As práticas educativas são diretamente afetadas diante desse cenário, tendo em vista que a educação é elevada ao papel central de formação de sujeitos comprometidos com os valores modernos. A criação de escolas para crianças e a preocupação com a instrução e a disciplina passa a ser o projeto de sociedade moderna (ARAUJO, 2009). A educação, especialmente na infância, passa a ser vista como modus operandi para uma transformação individual e social. O destaque dado à disciplina e à instrução infantil deixa evidente que o compromisso da Modernidade é com a transformação social e formação individual através de uma transmissão de conhecimentos por profissionais qualificados em espaços específicos para tal fim.

As ações sociais, incluindo as práticas pedagógicas, estão articuladas para consolidar a visão de mundo baseada na razão como instrumento de dominação da natureza e de outros humanos. A ideia de formação espiritual e moral vão paulatinamente dando espaço para uma prática educativa mais adensada aos fins utilitaristas de progresso e desenvolvimento.

Atrelada ao conceito de desenvolvimento econômico, a educação torna-se meio para o progresso, nos moldes europeus, de utilização exaustiva dos recursos naturais e exploração da força de trabalho humana. Há uma identificação, e até redução dos processos educacionais com o desenvolvimento cientifico-tecnológico. A Modernidade afasta a educação da mera contemplação espiritual e moral, a aproxima da vida e dos problemas cotidianos - trabalho, subsistência, consumo, etc. A fábrica e a escola passam a ser as instituições vitais. Há uma prevalência da visão pragmática das relações sociais, a qual liga a formação e conformação dos sujeitos. Como sintetiza John Dewey 
(1979, p. 227) "vida, experiência e aprendizagem não se separam".

Como sistema formado por valores e crenças variadas, a Modernidade traz em si diversos fundamentos, que, com as mudanças sociais, reconfiguram-se nessa correlação de forças. Tomando o Estado, o mercado e a comunidade como os elementos desse sistema, Santos, $(2011$, p. 56) afirma que ocorreu uma hipervalorização do mercado em detrimento do Estado e da comunidade, sendo esse último o mais renegado. A elevação do mercado ao centro das relações só foi possível diante do estabelecimento do desenvolvimento econômico e do progresso tecnológico como elementos fundamentais da sociedade.

As instituições passam a atuar envoltas no compromisso de manutenção e reprodução do sistema econômico que tem o trabalho e o consumo como pilares. A escola torna-se um ponto de tensão social, pois "a la educación se le asigna el rol de "valor agregado», $y$ «conocimiento humano», que permitirá a los países entrar en competítividad internacional". (MAGENDZO, 1994, p. 51). Como meio para realização dos fins econômicos e políticos, a educação vai se moldando e deixando de lado os interesses de liberdade, autonomia e dignidade humana, indicando uma "[...] tensão dialéctica entre regulação social e emancipação social". (SANTOS 2005, p. 1). A educação converte-se em instrumento de poder, pois é meio para o desenvolvimento e o progresso econômico diante da competitividade no mercado internacional.

O paradigma dominante na produção do conhecimento que emerge "[...] nega o caráter racional de todas as formas de conhecimento que se não pautarem pelos seus princípios epistemológicos e pelas suas regras metodológicas" (SANTOS, 2011, p. 61). Na Modernidade, os fundamentos que poderiam levar à realização e ampliação da liberdade e emancipação humana são absorvidos ou colonizados pela "racionalidade cognitivo-instrumental da ciência". (SANTOS, 2011, p. 55). O resgate dos fundamentos humanistas da educação moderna, submergido diante de um paradigma dominante, é capaz devolver à educação o compromisso com a liberdade, a emancipação e a autonomia humanas.

Olhando mais de perto, a Modernidade traz"[...] la apertura al cambio y a la existencia de multiplicidad de oportunidades, alternativas y opciones, [...] criticidad a los esquemas de la racionalidad instrumental [...]". (MAGENDZO, 1994, p. 51). É possível reflexionar sobre a Modernidade por dentro dos seus valores, o que permite rupturas e continuidades. Ao elevar a razão como guia das ações, as práticas podem ser sempre questionadas e remodeladas, sendo os processos educacionais propícios a esta finalidade. A um só tempo sustenta um conhecimento universal, mas por outro lado valoriza a investigação e o intercâmbio de ideias.

Na Modernidade, "o princípio da universalidade não se esgota numa 
reflexão monológica, ou seja, não se constitui como um a priori desde já válido" (LIMA, 2009, p. 305). Pode-se pensar na existência de um pluralismo de contextos concretos, "[...] a cultura e os sujeitos são marcados por uma variedade de formas simbólicas e formações identitárias específicas". (LIMA, 2009, p. 305). Os saberes gerais só podem ser formados a partir do diálogo e do intercâmbio permanente entre os sujeitos e seus saberes. Ao se adotar uma visão estanque e imutável, reproduzível em contextos sociais variados, tem-se a negação d potencialidade da razão como elemento central no pensamento moderno, que serviria à liberdade de pensamento e à crítica como produção de saberes.

A dominação como finalidade desarrazoa a produção de conhecimento, que elege como pensamento dominante "[...] confiar al funcionamiento del mercado la tarea de distribuir oportunidades en la educación". (MAGENDZO, 1994, p. 52). O modelo econômico arvora-se sobre os demais aspectos sociais, colonizando a produção dos saberes e guiando a formação de sujeitos. Tomando os termos que são próprios do capitalismo, a emergência desse paradigma dominante levou à divisão do mundo entre produtores e consumidores em matéria de conhecimento, "[...] economías rápidas y ricas que usan el conocimiento efectivamente, y economías pobres que no lo hacen". (MAGENDZO, 1994, p. 52).

Nas sociedades consumidoras/subdesenvolvidas/emergentes, a organização e a execução das práticas educacionais são desconectadas das necessidades locais e passam a seguir um padrão de interesse internacional, ditado pelas sociedades produtoras/desenvolvidas. Diante desse cenário organizativo do mundo, surge uma questão crucial: como promover a emancipação humana e o desenvolvimento econômico?

Uma primeira resposta diz que"[...] La solución para los países en desarrollo no es producir conocimiento sino que adquirirlo, adaptarlo y usarlo efetivamente". (MAGENDZO, 1994, p. 52). Tem-se a manutenção do processo de colonização, com a negação dos saberes locais, contextuais e particulares. As necessidades são impostas em termos universais, ou seja, os povos colonizados e colonizadores compartilhariam dos mesmos valores, interesses e fundamentos sociais. Essa proposta retira a autonomia, o reconhecimento e a possibilidade de participação e diálogo na construção dos elementos culturais aos quais estarão submetidos.

Outra resposta só é possível se forem identificados valores, interesses e finalidades sociais a partir dos saberes e práticas locais. Faz-se necessário tencionar o elemento comunitário e emancipatório da Modernidade, restringindo o campo de determinação econômico e ampliando o papel dos interesses humanos nas políticas sociais. Seguindo a tradição moderna de razão para análise, problematização e intercâmbio, os Direitos Humanos surgem no contexto da elevação da dignidade humana como fim social. Tais normas estão ligadas de modo indissociável à Democracia, a qual pressupõe o diálogo para o consenso, 
com por meio do reconhecimento e justiça social, valores que têm nas práticas de EDH um instrumento de difusão, promoção e fortalecimento.

\section{Direitos Humanos e globalização: transformações diante da diferença}

Da Modernidade advêm dois fenômenos que, nos últimos séculos, têm produzido uma profunda transformação nas culturas ao redor do mundo - Globalização e Direitos Humanos. Além de compartilhamento da gênese, há um forte entrelaçamento e mútua determinação reflexiva entre eles. Os Direitos Humanos representam um conjunto de normas e valores que foram alçadas à conquista universal, e como tal, levadas ao redor do mundo através dos processos de inter-relação política, econômica e cultural. De forma inevitável, após a assimilação, os povos não europeus passaram a questionar a validade universal dos fundamentos, práticas e fins dos Direitos Humanos.

Essa interação é complexa, por isso não pode ser explicada por uma única abordagem. A globalização não é acontecimento uniforme. Santos (2006) fala em globalizações, pois entende que esse conceito sempre designa um processo de dominação e a submissão. Para uma análise mais acurada, pode-se dividir o fenômeno em duas situações distintas: globalismo localizado e localismo globalizado (SANTOS, 2006). Essa dualidade recoloca os termos, percebendo a existência de um elemento particular na formação do discurso universal. Também aponta para alguns compromissos locais alinhados com interesses universais. A primeira situação identifica os países produtores de conteúdo (cultural, econômico e político) e a segunda os países receptores desses elementos.

Os Direitos Humanos estão inseridos nesse processo, em ambos os sentidos de globalização apontados por Santos (2006). Inicialmente, aponta Silveira (2008, p. 247), esse conjunto de normas "[...] remonta à chamada modernidade, ou modernidade clássica, nos séculos XVII-XVIII, enraizando-se nas revoluções liberais [...]". Nesse momento, apesar da formação discursiva da natureza universal dos Direitos Humanos, suas normas referem-se ao conjunto de cidadãos ligados politicamente ao Estado que os afirma. Tem-se, assim, um localismo, que irá se espalhar pelo globo à medida da expansão capitalista, com seus ideais de liberdade, cidadania e economia de mercado.

Buscando fixar um conceito para Direitos Humanos, Pérez Luño (1995, p. 18) afirma que é:

"[...] un conjunto de facultades e instituciones que, en cada momento histórico, concretan las exigencias de la dignidad, la libertad y la igualdad humanas, los cuales deben ser reconocidos positivamente por los ordenamientos jurídicos a nivel nacional e internacional". 
Apesar do elemento contextual, os compromissos dos Direitos Humanos estão ligados à dignidade, à liberdade e à igualdade, que podem ser encontrados, em níveis diferentes, em muitas culturas ao redor do globo. $\mathrm{O}$ grande desafio é preencher de sentido tais ideais em novos contextos de espaço-tempo, conforme as necessidades sociais presentes.

Para Silveira (2008, p. 248), a "cultura burguesa ocidental [...] reuniu os que pensaram/pensam universalizar os direitos liberais, de modo a atingirem os mais diversos povos, sociedades e segmentos sociais.." Os demais Estados e povos, como receptores, devem fazer uso desse conjunto de valores, os quais estão prontos para concretizar a dignidade de todos os humanos, independe de quem seja ou onde esteja. A cultura local deve abrir espaço para que os Direitos Humanos possam guiar a formulação de políticas e as ações individuais concretas. Nesse aspecto, há uma verdadeira dominação, substituição de um arcabouço simbólico por outro, tido como mais adequado aos fins da Modernidade.

Ao tempo que expandem o domínio político e econômico sobre os demais povos e Estados, os localismos globalizados produzem furos ou aberturas na dinâmica e na cultura locais, as quais fazem surgir os globalismos localizados, conforme Santos (2006). O autor cita processos como a exploração econômica dos recursos humanos, naturais e culturais - zonas de livre comércio, uso não sustentável dos recursos ambientais para saldas dívidas externas, a transformação da agricultura em agronegócio de exportação - nos países periféricos, como exemplo de ações locais para benefícios globais. Ao invés de representar um processo de interação horizontal e trocas socioculturais, a Globalização "[...] é o processo pelo qual determinada condição ou entidade local estende a sua influência a todo o globo e, ao fazê-lo, desenvolve a capacidade de designar como local outra condição social ou entidade rival". (SANTOS, 2005, p. 3).

Segundo Canclini (2006, p. 1), a globalização "[...] acentua a interdependência entre muitas sociedades e gera novos fluxos e estruturas de inter-relações supranacionais". Não há horizontalidade no processo, pois a visão de mundo europeia/ocidental é alçada à única possível, fazendo surgir uma rede de dependência global, a qual sobrepõe os interesses e necessidades locais. Surge uma forma específica de organização social, voltada ao desenvolvimento tecnológico e ao progresso econômico. Além de descolar-se dos outros fins e interesses sociais, a finalidade tecnológico-econômica ultrapassou as fronteiras estatais criando organismos internacionais de gestão de interesses do mercado.

Conforme Ramos e Frangella (2013, p 15), “[...] uma nova ordem mundial se instalou nos últimos 20 anos do século XX, marcada pela ideia de que competição em um mercado livre da interferência do Estado pode regular tudo". O Estado Moderno, enquanto elemento de síntese de uma nação, deixa de ser o protagonista das relações internacionais. Os interesses locais emer- 
gentes são assimilados aos interesses econômicos e políticos ou transformados em mercadoria, sem abalar as estruturas que mantém o Mercado.

A cultura local deixa de ser objeto de conflito e passa a ser o elemento para dominação. O mercado é difuso e adaptável, ao contrário do Estado, que está apegado à interesses pouco maleáveis. Com a elevação da força social do mercado, "[...] o consumismo invadiu as formas de negociação da identidade, do status e da influência política das pessoas [...]" (YUDICE, 2006, p. 20). A cultura passa a ser mercadoria especial, tonando-se o uma importante peça de articulação para disciplina e dominação por meio da organização e distribuição dos bens culturais. Desde que não seja ameaça a modelo global, as culturas locais são conservadas e adaptadas.

Além do processo de dominação internacional, produziram-se processos internos de dominação, os quais mantém os mesmo fundamentos e compromissos. Essa relação pode ser expressa no conceito de colonialismo interno (CASANOVA, 2007). Há conflitos entre aqueles que se opõe aos ideais universais estrangeiros, geralmente as minorias étnica e racial, que têm uma visão de mundo diversa daquela apresentada pelos colonizadores / desenvolvidos / produtores, e os que se apropriam desses ideais para assumir o exercício do poder em continuidade colonial. A disputa pelo poder passa a ser baseada nos valores culturais, não mais na distinção geográfica dos personagens.

Em decorrência desse conflito interno e externo, formou-se, na atualidade, uma reflexão crítica às "[...] noções clássicas de verdade, razão, identidade e objetividade, a idéia de progresso ou emancipação universal, [...] vê o mundo como contingente, gratuito, diverso, instável, imprevisível". (EAGLETON, 1996, p. 7). Os objetivos e fundamentos da Modernidade são questionados e reformulados, em decorrência dos contextos em que esse discurso passa a ser ventilado. As críticas apontam que o processo de emancipação humana pela razão moderna mantém-se inconcluso ou foi abandonado em prol de um eficiente e concluso processo de dominação humana.

Conforme Bittar (2009, p. 100), "a racionalidade que emerge da modernidade não esgota a noção de razão e não realiza plenamente a ideia de razão. A racionalidade que emerge da modernidade é um minus com relação à própria idéia, em potencial, da razão". O encontro dos interesses europeu-universal com as necessidades-periféricas produziu o "[...] alargamento das críticas dirigidas ao primado da racionalidade ocidental e introduziu, nos fenômenos sociais, desafios e leituras contemporâneas". (RAMOS; FRANGELLA, 2013, p 15). Ao invés de criar dóceis mercados consumidores e fornecedores de matéria prima, a globalização faz emergir profundos descontentamentos entre os benefícios locais e globais da integração mundial. Os Direitos Humanos, nas ex-colônias europeias, passam a servir de instrumento de questiona- 
mento das prioridades da sociedade moderna, que eleva à máxima o modelo econômico, tencionando as contradições internas e as possibilidades existentes.

Com a pretensão de universalidade, os europeus atribuíram a si mesmos o "[...] poder de nomear pela primeira vez o mundo; de traçar fronteiras para estabelecer quais conhecimentos são legítimos e quais são ilegítimos, definindo quais comportamentos são normais e quais são patológicos". (CASTRO-GÓMEZ, 2005, p. 18). O apontamento dessa pretensão como falácia, permite repensar a produção de conhecimento e o papel da razão como instrumento de modificação do mundo. Os Direitos Humanos ganham uma perspectiva histórica e contextual, ao invés de substituição de valores e negação das visões de mundo não europeias, há uma profunda busca por identificação e reconhecimento da dignidade humana multifacetada.

Como discurso de tensão inata, os Direitos Humanos "[...] constituem uma classe variável, [...] no futuro, poderão surgir novas pretensões que no momento sequer podemos imaginar [...]. O que demonstra que não existem direitos por natureza" (BOBBIO, 2004, p. 18). Os humanos, aos quais os direitos são destinados, têm necessidades socialmente determinadas, o que impede uma homogeneização global de todos as suas bandeiras. Há uma ressignificação dos Direitos Humanos, como consequência da reflexão sobre o projeto social da Modernidade, que "[...] em suas múltiplas faces, encontra-se fragmentado mas não extinto" (LIMA, 2009, p. 304). A mesma razão que serviu à dominação, "[...] reduzida a meio, desproveu a ação humana de sentido e tecnificou a própria racionalidade" (ibidem), pode servir ao questionamento e à crítica reflexiva, elevando o diálogo e a participação aos pilares da produção de saberes.

A principal mudança no contexto dos Direitos Humanos, nos últimos anos, diz respeito à resistência daqueles que não estão inseridos no contexto cultural burguês, "[...] vão emergindo e se constituindo formas de resistência - a exemplo das lutas das classes trabalhadoras européias no século XIX e das lutas anticoloniais no século XX [...]" (SILVEIRA, 2008, p. 249). É possível vislumbrar demandas particulares, desenhadas na América Latina do período pós-colonial ao contemporâneo. Os interesses locais visão a implementação e fortalecimento da democracia, o reconhecimento multicultural, o estabelecimento de diálogo com os saberes dos povos nativos e a promoção da justiça social.

A resistência política dos Direitos Humanos foi incrementada com a inclusão da noção de reconhecimento como essencial à dignidade humana, ao lado das demandas por justiça social. Hoje, as "demandas por 'reconhecimento das diferenças' alimentam a luta de grupos mobilizados sob as bandeiras da nacionalidade, etnicidade, raça, gênero e sexualidade [...]" (FRASER, 2001, p. 245). Os movimentos se complementam na busca por autodeterminação econômica e política e reconhecimento da diferença e negação da subalterni- 
zação dos saberes locais.

O conjunto de normas que forma os Direitos Humanos está redimensionado, em quantidade e em temas, há "[...] uma perspectiva mais ampla dos direitos, para além das experiências liberais e das lutas socialistas". (SILVEIRA, 2008, p. 249). Em locais periféricos, como a América Latina, os Direitos Humanos ganham um novo pano de fundo e, portanto, conteúdo e finalidades. Tais processos e mudanças refletem na $\mathrm{EDH}$, instrumento para reflexão sobre as relações sociais e práticas pedagógicas, por meio da adoção e manutenção de modelos democráticos e dialógicos na produção do conhecimento.

Usando o conjunto ético-normativo de proteção à liberdade, à emancipação e à dignidade humana, a EDH está comprometida com "[...] a desmercadorização, a desprivatização dessas relações [sociais] e a sua conversão como bens públicos, para a espécie.." (SILVEIRA, 2008, p. 262). Há uma possibilidade de redimensionamento das finalidades dos processos sociais, incluindo os educativos, deixando os interesses do Mercado em um plano secundário, para alçar a concretização da dignidade, participação e reconhecimento como guias primários.

Ao lado do reconhecimento multicultural e busca por justiça social, a EDH nega a universalidade a priori de todo conhecimento produzido pelos europeus, afirmando a essencialidade do diálogo para a promoção do conhecimento. Nega la hybris del punto cero (imaginário do ponto zero) que "[...] pretender hacerse un punto de vista sobre todos los demás puntos de vista, pero sin que de ese punto de vista pueda tenerse un punto de vista". (CASTRO-GÓMEZ, 2007, p. 83). Se o conhecimento europeu estava comprometido com colonização de outros territórios e seres humanos, na América Latina, o conhecimento está comprometido com a descolonização dos saberes e a autonomia dos seres humanos.

\section{Educação em direitos humanos na América Latina: diálogo e participação}

A educação moderna tem dois grandes fins - emancipar e regular (ESTEVÃO, 2013). Com o grande êxito do modelo econômico e social capitalista, a educação está comprometida com a conformação dos sujeitos a este modelo. Segundo a axiologia do Mercado, a escola passa a ser local de consumo, na qual os clientes ou consumidores adquirem um bem segundo a lógica de "vender bem" ou "ser eficiente e eficaz" (ESTEVÃO, 2013, p. 32). As possibilidades e fins das práticas educacionais, em última análise, estão direcionadas a objetivos delimitados pelas noções econômicas de progresso e desenvolvimento.

Os Direitos Humanos, em seu processo de ampliação e renovação de interesses, pode ser um ponto de ruptura, realinhando os objetivos sociais a criação de condições adequadas para o exercício pleno da dignidade por todos 
os seres humanos. Para isso, a EDH pressupõe como condição a"[...] participação substantiva da comunidade escolar nas decisões que a afectam, sem coações, dentro dos pressupostos de uma abordagem deliberativa e comunicativa de democracia" (ESTEVÃO, 2013, p. 32). As práticas de EDH estão organizadas sob a ideia de diálogo e emancipação dos sujeitos, tendo como fins a formação de pessoas autônomas e participativas, não trabalhadores e consumidores conformados.

Com o realinhamento dos fundamentos das práticas sociais e educacionais, a EDH é dialógica, "[...] dá a todos a possibilidade de justificar e de argumentar, [...] conduz a aprender a cooperar, a partilhar, a respeitar diferenças, a ser solidários" (ESTEVÃO, 2013, p. 32). Estando atrelada ao contexto e, ao mesmo tempo, sendo instrumento de reforço ou transformação, a forma educativa/pedagógica é determinada pelos fundamentos de organização social geral. Assim, em contexto autoritário, no qual o diálogo não é ferramenta de produção social, é improvável a existência de práticas educativas fundamentadas na participação.

$\mathrm{Na}$ América Latina, somente após lançar as bases para o exercício da cidadania democrática, foi possível construir uma educação fundamentada nos Direitos Humanos. Não há EDH sem o contexto social e institucional necessários à sua prática. Rodino (2016, p. 96) aponta que:"La EDH apenas comienza a esbozarse como una aspiración legítima en los sistemas educativos, favorecida por las transiciones democráticas producidas entre mediados y finales de los años 1980 en la mayoría de los países de la región". Em processo cíclico, a EDH é sustentada em práticas dialógicas e fortalece o compromisso com processos democráticos.

A partir das décadas de 1960 e 1970, nas quais são produzidos documentos internacionais proteção aos oprimidos (crianças, mulheres, negros, povos originários, etc.), surgem articulações populares de adoção ampliada de Direitos Humanos, voltada aos interesses e necessidades locais. Diante dos governos autoritários espalhados por diversos países da América Latina, na década de 1980, segundo, Zenaide (2016, p. 49) há “[...] emergência de organizações combativas, movimentos de massa, sindicais e populares que passaram não só atuarem na resistência contra o autoritarismo, como nas lutas por justiça social e políticas públicas [...]". A modificação das estruturas autoritárias de poder, comprometidas com o êxito do modelo europeu de economia de mercado e produção de conhecimento baseado em interesses globais, faz parte do cerne da EDH na América Latina.

Diante da necessidade de ampliação da participação popular e reconhecimento das diversidades locais, a EDH "[...] significa articular diferentes campos do conhecimento num diálogo interdisciplinar, relendo as fontes históricas e reconstruindo trajetórias de lutas em defesa dos direitos humanos". (ZENAIDE, 2016, p. 39). Há uma ruptura com os fundamentos das práticas educativas da Modernidade, pois não está centrado na universalidade do conheci- 
mento. Os colonialismos internos são expostos, desnudando o contexto de subalternização vivenciado pelos saberes e povos originários da América Latina.

Na luta contínua contra as mais diversas formas de opressão, "[...] adquirem especial relevância as atividades de promoção e educação em Direitos Humanos" (CANDAU, 2016, p. 401). A educação que daí ressurge está comprometida com a diversidade, a participação e o diálogo, deixa de lado uma percepção monológica como fundamento para a produção do conhecimento e das práticas educativas. Há um verdadeiro resgate, por outras vias, do projeto moderno de emancipação humana, agora explicitado nos Direitos Humanos. Alinhado aos movimentos internacionais de afirmação de direitos, de combate ao autoritarismo e lutas anticoloniais, a América Latina é palco de grandes transformações socialdemocratas. Nos anos 1980, depois das primeiras experiências de educação popular e emancipadoras, começam as primeiras práticas educativas governamentais em Direitos Humanos, as quais são elevadas na década 1990 a políticas educacionais em escolas públicas. Mas somente nos anos 2000 é que são criadas redes mundiais e regionais de estudos e pesquisas, com a profissionalização e especialização da educação em Direitos Humanos, em programas pós-graduação e nos movimentos sociais (RODINO, 2016).

A EDH na América Latina é recente, produto do encontro de educadores populares e militantes em prol desse conjunto de Direitos Humanos. Dos educadores populares vem o comprometimento com "[...] la demanda de la participación, en oposición a formas educativas autoritarias " (SIME, 1994, p. 94). Há uma revalorização do conflito como força produtora, vistos de forma positiva como espaços de promoção e exercício da dignidade humana. Por evidente, há mais uma ruptura com função tradicional das práticas pedagógicas modernas de "[...] crear grupos que compartieran valores comunes por encima de sus peculiaridades; es decir, formar ciudadanos homogéneos [...]" (ESPEJO, 2012 , p. 242). A crítica e o conflito, que marca esse espaço-tempo, vai contra a homogeneidade voltada ao exercício de papeis sociais passivos - trabalhador e consumidor -, segundo os interesses delineados pelo Mercado.

Ao invés de negar a existência de necessidades e interesses locais, a EDH vai no sentido de"[...] el reconocimiento de las diferencias de cada grupo o con los contextos locales [...]" (ESPEJO, 2012, p. 242). O reconhecimento das diferenças toma os Direitos Humanos e a razão da Modernidade como instrumentos para a emancipação humana. A ruptura com a universalidade moderna dá-se pela introdução do diálogo entre diferentes saberes e práticas sociais como elemento para a produção do conhecimento. Ao final, tem-se a reabilitação do sentido original de razão como instrumento para a liberdade e emancipação iluminista.

As práticas educativas baseadas no respeito à diferença e comprometidas com a realização da dignidade humana só são possíveis em contextos 
sociais democráticos. Na América Latina, fortalece-se a perspectiva de que não há "[...] una ideología, un partido, una iglesia, una organización no gubernamental, una organización popular dueña de los derechos humanos, representante única del pueblo, y vocera exclusiva de la verdad" (SIME,1994, p. 88). Ao invés de compromissos exclusivos com direitos civis e políticos, a prática educativa em EDH vai sendo preenchida pela ideia de justiça social, a qual comporta o acesso a direitos sociais, culturais e econômicos, com respeito aos saberes locais e em harmonia com o meio ambiente.

Tomando a participação como um dos elementos centrais da justiça social, é possível identificar um fundamento político na prática de EDH, direcionado à crítica das relações sociais, a qual permite "[...] reconocer cuáles son los motivos reales que están en la raíz de nuestros problemas y de las injusticias" (MAGENDZO, 2016, p. 234, 235). A EDH pressupõe o reconhecimento do outro como membro e participante da comunidade baseada no diálogo. Ao invés da negação de humanidade às minorias étnicas e sociais, ampliam-se as similaridades e os interesses comuns. A EDH permite que os reais problemas sociais sejam entendidos, permitindo uma atuação autônoma e emancipada.

Desde os primeiros acenos, "[...] la educación en derechos humanos reivindicó su compromiso con la justicia social desde sus inicios en el trabajo con los movimientos sociales y la educación popular inspirada en el pensamiento de Pablo Freire" (MAGENDZO, 2016, p. 221). O contexto sócio-histórico faz emergir um sentido próprio para o conjunto de normas dos Direitos Humanos, ligando-o à justiça social. Além dos compromissos com direitos civis e políticos, tem-se o acesso a direitos sociais, culturais e econômicos, o respeito aos saberes locais e a harmonia com o ambiente, como conteúdo a EDH na América Latina. Em reforço dessa perspectiva, para Vargas (2011, p. 24), "[...] implica plantearse las posibilidades, condiciones y contenidos de una pedagogía del 'campo político' [...]", por isso, uma educação para a cidadania.

As mudanças na dinâmica social da América Latina, especialmente diante ruptura com os saberes locais, a qual se manteve através das alianças e compromissos entre as elites locais e os interesses europeus, delinearam os fundamentos da EDH no continente. Segundo Candau a EDH está comprometida com: "[...] formar sujeitos de direito, favorecer processos de empoderamento e educar para o 'nunca mais' [...]". (CANDAU, 2011, p. 405). Com tais propósitos, deve-se promover o diálogo e a participação por meio da "[...] utilização de metodologias ativas, participativas, de diferentes linguagens [...]" (p. 405) e que integrem os saberes cientificamente sistematizados aos socialmente produzidos. O conhecimento dos eventos passados, sejam as conquistas, sejam as mazelas autoritárias, permite formar uma sociedade comprometida com valores que tenham o ser humano e comunidade como fundamento e finalidade. 
Esse modelo educacional, no aspecto organizativo e executivo, comprometido com a cidadania e a participação, tem expressão no plano normativo interamericano. O Protocolo de San Salvador, ao tratar do direito à Educação, delineia alguns fundamentos de suas práticas, a qual "deverá fortalecer o respeito pelos direitos humanos, pelo pluralismo ideológico, pelas liberdades fundamentais, pela justiça e pela paz" e "deve capacitar todas as pessoas para participar efetivamente de uma sociedade democrática e pluralista" (OEA, 1988). No sentido do documento, não há EDH sem que haja acesso à educação no sentido amplo, que deve estar orientada por valores democráticos. Mesmo com a elaboração de documentos jurídico e estratégicos, as forças sociais muitas vezes não caminham em um sentido único.

Após a descolonização europeia, a colonização interna é ainda o principal obstáculo à concretização de práticas educativas emancipadoras e cidadãs. O contexto do século XX e XXI está marcado pela substituição de ditaturas liberais por democracia neoliberais, as quais, quase todas, "[...] têm legislações orientadas a promover e instituir a educação em Direitos Humanos nos sistemas de ensino." (CANDAU, 2016, p. 403). Hoje os desafios da EDH "[...] pasan por consolidar su presencia como saber y como pedagogía de los derechos humanos en todos los componentes del sistema educativo" (RODINO, 2016, p. 121). Não basta apenas a elaboração de programas, planos ou diretrizes educacionais, é necessário modificar as estruturas institucionais, de tal modo que seja possível o exercício da participação e valorização dos saberes locais.

No processo de criação de políticas públicas educacionais, é comum atrelar a noção de cidadania a "[...] la nacionalidad y a la pertenencia a una comunidad dentro de un territorio cerrado y con una cultura homogénea [...]" (RODINO, 2016, p. 108). Se isso acontece, tem-se um enfraquecimento do diálogo e da participação, tendo em vista que o sentido adotado mantém um caráter de segregação. Além dos sentidos fracos, na proposição da emancipação humana, a polissemia da expressão Direitos Humanos e Educação em Direitos Humanos - EDH, pode, por vezes, produzir um esvaziamento de sentido, o que acaba neutralizando a proposta de transformação social.

Pode-se identificar, segundo Vargas (2011, p. 25), pelo menos dois modelos de educação em disputa atualmente. Um comprometido com as "[...] dinámicas del tecno-capitalismo (concentración del poder, 'mercadismo' extremo, exclusión estructural, monopolización del conocimiento) [...]". O outro é o modelo de educação para a cidadania, que tem as demandas democráticas como seu fundamento e fim, portanto direcionada para a participação, o fortalecimento da comunicação e da interação social daqueles que são excluídos e oprimidos pela dinâmica da economia de mercado.

O modelo social, político e educacional, que se tornou hegemônico a 
partir da Modernidade, tendo o desenvolvimento tecnológico e o progresso econômico como fins últimos, por muitos anos foi sustentado por governos autoritários. A ausência de diálogo e participação impede que os interesses e as necessidades comunitárias sejam elevados a produtoras de diretrizes sociais. Na América Latina, com o fim de regimes ditatoriais, a volta de eleições diretas e os movimentos em torno da democratização, é que se pode identificar a "[...] década de 1980 como um momento privilegiado para a emersão de propostas pedagógicas contra-hegemônicas" (SAVANI, 2013, p. 413).

Como proposta de modificação das práticas educacionais, as correntes críticas ao modelo hegemônico tinham no"saber do povo e na autonomia de suas organizações" sua base, pretendendo que as escolas se tornassem "[...] espaços de expressão das ideias populares e de exercício da autonomia popular [...]" (SAVANI, 2013, p. 415). Seguindo as reinvindicações que já estavam em curso, os movimentos educacionais em torno dos Direitos Humanos questionam a validade universal dos saberes europeus como fundamentos das práticas sociais globais.

A EDH está, desde a origem, comprometida com valores democráticos, dialógicos e participativos. Ao invés de um conceito restritivo de cidadania, assenta-se na ideia de "[...]'ciudadanía global', que plantea que somos ciudadanos del globo y debemos reconocer nuestras responsabilidades hacia cada uno de nuestros semejantes y nuestro hábitat común [...]" (RODINO, 2016, p. 108-109). Há uma ampliação do compartilhamento dos deveres e direitos, fundamentando uma relação social baseada em pressupostos não autoritários e inclusivos. Esse movimento não é linear, nem uniforme. Cabe reflexão constante sobre a EDH para que os fundamentos sócio-históricos não sejam menosprezados, nem o contexto das relações sociais negados sob o argumento de aplicação de saber universal.

\section{Considerações finais}

O projeto de sociedade da Modernidade tem como particularidade a pretensão de universalidade. Como produto das relações, valores e fundamentos sociais, representa uma visão de mundo de determinada cultura. A proposta não foi elaborada para ser aplicada apenas no espaço-tempo europeu, mas para colonizar outros povos e culturas, tornando aquele modelo hegemônico. Os seus principais elementos estão ligados à economia de mercado, ao poder político centralizado na figura do Estado e à sociabilidade voltada ao desenvolvimento e ao progresso tecnológico-econômico.

Os fundamentos modernos tomam forma mais precisa a partir dos séculos XVI, os quais irão justificar e legitimar a colonização europeia de outros 
povos e territórios, substituindo a visão de mundo local pelos modelos econômico capitalista, político estatal e social individualista. Para implementar tal projeto, a educação foi elevada a instrumento de formação e conformação do sujeito, que seria liberto dos limites impostos pela natureza e pela comunidade, ao mesmo tempo que estaria conformado à nova sociabilidade vigente.

Sendo analisada de perto, a Modernidade traz em si tensões e contradições congênitas, acentuadas pelas noções de emancipação e regulação, produzindo uma ressignificação constante de seus elementos. Tal processo pode ser visto na dinâmica de formação e transformação dos Direitos Humanos, enquanto conjunto de normas sociais comprometidas com a dignidade humana.

Desde as primeiras normas de garantia de liberdades individuais, civis e políticas, o que de mais importante tem acontecido com o conjunto de normas dos Direitos Humanos é a ampliação temática e geográfica. Novas demandas foram sendo inseridas, especialmente aquelas que dizem respeito à justiça social, reconhecimento das diferenças multiculturais e pluralidade de visões de mundo.

O superdimensionamento das normas de Direitos Humanos tomou como impulso o processo de globalização, o qual permitiu o contato e a interação, mesmo que de forma assimétrica, entre variados interesses e demandas sociais. O projeto de sociabilidade da Modernidade foi imposto por meio do processo de colonização, que se mantive por outras vias após o rompimento do domínio político estrangeiro direto. Parcela da população local, ao se comprometerem com este projeto, substituíram os europeus na negação dos interesses locais, canalizando os recursos humanos e naturais para a satisfação das demandas globais.

O aumento das contradições locais levou ao questionamento da validade universal daqueles saberes. O desenvolvimento e o progresso não se tornaram realidade, nem houve melhoria uniforme da qualidade de vida. Os Direitos Humanos não foram universalizados na mesma velocidade que o modelo econômico, deixando um vazio nas promessas da Modernidade como conjunto de saberes absolutos.

Desde o primeiro contato dos europeus com os povos originários da América Latina, as palavras de ordem foram segregação e autoritarismo, cartilha seguida por todos os compromissados - locais ou estrangeiros - com a implementação de uma sociedade naqueles moldes. Nesse interim, a colonização mudou de atores, mas não de ações, ainda baseada na ausência de diálogos, em governos antidemocráticos e negação dos saberes locais. A luta por democracia e participação não esteve dissociada dos questionamentos sobre todo o sistema baseado na universalidade de interesses e saberes.

Os Direitos Humanos, ao serem adotados nesse contexto, tornaram-se instrumento de crítica sobre as possibilidades e realizações da Modernidade, 
abrindo espaço para repensar a relação de dominação multifacetada até então em curso. Pelo menos desde os anos 1960, na América Latina, as lutas populares e democráticas têm no diálogo plural e na participação inclusiva suas bandeiras de ação. Aproveitando a centralidade da educação na Modernidade, as práticas educativas tornaram-se importantes elementos de emancipação local, redirecionadas à promoção de estruturas sociais dialógicas, como nas ações da educação popular e movimentos pró-democráticos dos anos 1970 e 1980.

Ao longo dos anos 1900 e 2000 ocorreu, no continente americano, a inserção da EDH na educação formal, nos mais variados níveis. Ainda assim, o esvaziamento de sentido e a utilização de metodologias não-participativas representam desafio para a realização da $\mathrm{EDH}$, fundamentada no diálogo com os saberes e práticas locais e no fortalecimento de instituições democráticos e cidadãos participativos.

Da educação básica ao ensino superior, incluindo os espaços de formação técnica, educação não-formal e os sistemas de justiça e segurança, é necessário que os valores e as normas de Direitos Humanos orientem as práticas pedagógicas nos níveis da organização e da execução. Os planos, projetos e programas pedagógicos precisam adotar os valores da liberdade, da justiça social, da pluralidade e da sustentabilidade socioambiental como estruturantes. Os conteúdos precisam ser permeados por esses mesmos temas, através de temas transversais, em práticas interdisciplinares ou em disciplinas específicas.

$\mathrm{Na}$ América Latina, a EDH precisa ser repensada de forma permanente para não correr o risco de ser colonizada pelos interesses que não tenham na dignidade humana a sua finalidade. Os saberes locais precisam ser reabilitadose inseridos nos fundamentos das práticas educativas, promovendo diálogos que tenham no reconhecimento da diferença e na justiça social elementos constitutivos. Os espaços educativos devem tomar a democracia participativa como eixo organizador, criando estruturas capazes de abrigar práticas adequada aos contexto sócio-histórico, servindo para repensar os processos formativos, os interesses e os fins diretivos das práticas educacionais.

\section{Referências}

ARAÚJO, José Carlos Souza. Haveria uma antropologia infantil na modernidade? Revista Educação em Questão, Natal, v. 36, n. 22, p. 74-113, set./dez. 2009. Disponível em: https://periodicos.ufrn.br/educacaoemquestao. Acesso em: 21 out. 2020.

BITTAR, Eduardo C. B. Razão e afeto, justiça e direitos humanos: dois paralelos cruzados para a mudança paradigmática. Reflexões frankfurtianas 
e a revolução pelo afeto. Revista Mestrado em Direito, Osasco, Ano 8, n.1, p. 99-128, 2008.

BOBBIO, Norberto. A era dos direitos. Tradução Carlos Nelson Coutinho. 9. reimp. Rio de Janeiro: Elsevier, 2004.

CAMBI, Franco. História da pedagogia. Tradução de Álvaro Lorencini. São Paulo: Fundação Editora da UNESP (FEU), 1999.

CANDAU, Vera Maria. Educação em direitos humanos: desafios atuais. In: Ana Maria Rodino et al., Cultura e educação em direitos humanos na América Latina. Brasil: trajetórias, desafios e perspectivas. João Pessoa: CCTA, 2016.

CASANOVA, Pablo González. Colonialismo interno (uma redefinição). In: A teoria marxista hoje. Problemas e perspectivas. Buenos Aires: CLACSO, Consejo Latinoamericano de Ciencias Sociales, 2007.

CASTRO-GÓMEZ, Santiago. La hybris del punto cero. Ciencia, Raza e llustración en la Nueva Granada (1750-1816). Bogotá: Pontificia Universidad Javeriana, 2005.

CASTRO-GÓMEZ, Santiago. Decolonizar la universidad. La hybris del punto cero y el diálogo de saberes. In: CASTRO-GÓMEZ, Santiago; GROSFOGUEL, Ramón (org.). El giro decolonial: reflexiones para una diversidad epistémica más allá del capitalismo global. Bogotá: Siglo del Hombre Editores;

Universidad Central, Instituto de Estudios Sociales Contemporáneos y Pontifi cia Universidad Javeriana, Instituto Pensar, 2007.

EAGLETON, T. As Ilusões do pós-modernismo. Rio de Janeiro: Jorge Zahar,1996.

ESPEJO, Juan Cornejo. Educación, interculturalidad y ciudadanía. Educar em Revista, Curitiba, n. 43, jan./mar., p. 239-254, 2012. Disponível em: https:// www.scielo.br/pdf/er/n43/n43a16.pdf. Acesso em: 24 nov. 2020.

ESTÊVÃO, Carlos Alberto Vilar. Democracia política, democracia escolar e educação para os direitos humanos. Educação, Porto Alegre, v. 36, n. 1, p. 2834, jan./abr. 2013.

FRASER, Nancy. Da redistribuição ao reconhecimento? Dilemas da justiça na era pós-socialista. In: SOUZA, J. (org.). Democracia hoje: novos desafios para a teoria democrática contemporânea. Brasília, DF: UnB, 2001. 
FRASER, Nancy. Reconhecimento sem ética? Lua Nova, São Paulo, n. 70, p. 101-138. 2007. Disponível em: http://www.cedec.org.br/mediacoes-dificeis--ano-2007---no-70. Acesso em: 25 nov. 2020.

GIDDENS, A. As consequências da modernidade. São Paulo: Editora da Universidade Estadual Paulista, 1991.

LIMA, João Francisco Lopes de. A educação, a pós-modernidade e a crise de fundamentação do discurso pedagógico. Cadernos de Pesquisa: Pensamento Educacional, Curitiba, v. 4, n. 7, p. 297-315, 2009.

MAGENDZO, A. La Educación en derechos humanos desde la modernidad y la postmodernidad. In: MAGENDZO, A. (org.) Educación en Derechos Humanos: apuntes para una nueva práctica. Chile: Corporación Nacional de Reparación y Reconciliación e PIIE, 1994.

MAGENDZO, Abraham. La educación en derechos humanos y la justicia social en educación. In: RODINO, Ana Maria et al., (org.). Cultura e educação em direitos humanos na América Latina. Brasil: trajetórias, desafios e perspectivas. João Pessoa: CCTA, 2016.

MARQUES, Eliana de Sousa Alencar; CARVALHO, Maria Vilani Cosme de. O significado histórico de práticas educativas: um movimento que vai do clássico ao contemporâneo. Linguagens, Educação e Sociedade, Teresina, Ano 21, n. 35, jul./dez, p. 122-142, 2016.

ORGANIZAÇÃO DOS ESTADOS AMERICANOS (OEA). Protocolo adicional à convenção americana sobre direitos humanos em matéria de direitos econômicos, sociais e culturais, "Protocolo de San Salvador". San Salvador, El Salvador, 1988. Disponível em: https://www.gov.br/mdh/pt-br/navegue-portemas/atuacao-internacional/relatorios-internacionais-1/protocolo-adicionala-convencao-americana-sobre-direitos-humanos-em-materia-de-direitoseconomicos-sociais-e-culturais-protocolo-de-san-salvador. Acesso em: 26 abr. 2021.

PÉREZ LUÑO, Antonio Enrique. Derechos humanos, estado de derecho y constitución. Madrid: Tecnos, 1995.

RODINO, Ana Maria. La institucionalización de la educación en derechos humanos em los sistemas educativos de américa latina (1990 - 2012): avances, limitaciones y desafíos. In: RODINO, Ana Maria et al. (org.). Cultura e 
educação em direitos humanos na América Latina. Brasil: trajetórias, desafios e perspectivas. João Pessoa: CCTA, 2016.

SANTOS, Boaventura de Sousa. A gramática do tempo: para uma nova cultura política. São Paulo: Cortez, 2006.

SANTOS, Boaventura de Sousa. Para um novo senso comum: a ciência, o direito e a política na transição paradigmática. 8. ed. São Paulo: Cortez, 2011.

SAVIANI, Dermeval. História das ideias pedagógicas no Brasil. 4. ed. Campinas, SP: Autores Associados, 2013.

SILVEIRA, Rosa Maria Godoy. Educação em/para os direitos humanos: entre a universalidade e as particularidades, uma perspectiva histórica. In: SILVEIRA, R. M. G. et al. Educação em Direitos Humanos: fundamentos teóricometodológicos. João Pessoa: Editora Universitária, 2008.

SIME, L. Educacion, persona y proyecto histórico. In: MAGENDZO, A. (org.) Educación en Derechos Humanos: apuntes para una nueva práctica. Chile: Corporación Nacional de Reparación y Reconciliación e PIIE, 1994.

VARGAS, Jorge Osorio. Educación en Derechos Humanos en América Latina: pedagogía del campo político y aprendizaje de la ciudadanía democrática. Paulo Freire. Revista De Pedagogía Crítica, Santiago de Chile, Chile, n. 10, p. 23-34, 2011. Disponível em: http://revistas.academia.cl/index.php/pfr/ article/view/428. Acesso em: 24 nov. 2020.

ZENAIDE. Linha do tempo da educação em direitos humanos na américa latina. In: Ana Maria Rodino et al. Cultura e educação em direitos humanos na América Latina. Brasil: trajetórias, desafios e perspectivas. João Pessoa: CCTA, 2016.

Recebido em: 21 de janeiro de 2021.

Aprovado em: 20 de abril de 2021 